\title{
REHABILITATION OF Historical CITIES IN THE Mediterranean uSing Modular Patterns - CaSe STUDY OF SIDON
}

\author{
Fouad A. Ghoussayni, Amer Ali and Ali Bayyati \\ School of the Built Environment and Architecture, London South Bank University \\ London, United Kingdom \\ ghoussaf@1sbu.ac.uk
}

(Received September 2018 - Accepted November 2018)

\begin{abstract}
A. Ghoussayni, F. Ali, A. and Bayyati, A. 2018. Rehabilitation of Historical Cities in the Mediterranean using Modular Patterns-Case Study of Sidon. Lebanese Science Journal. 19(3): 410-431.

Over the Eastern Mediterranean Coast, a historical centre, well known as the port of the Phoenicians, stands facing the sea where ships sail across the blue horizon. There lie the oldest historical monuments of Sidon that remain undocumented. This paper's aim is to study these buildings that have been damaged by urbanization by using methodological norms and predict their social practices that were inhabited with the lifestyle of fishermen and by which we came across many repetitive patterns that turned out to be modular. By envisaging the modular spatial practices of ruined buildings, their cores of which we had no previous information, we can restore those buildings to their original state.
\end{abstract}

Keywords: Sidon, Saida, Conservation, Renovation, Town and City Planning, Land Surveying, History.

\section{INTRODUCTION}

The word Sidon is entangled with its translation as 'fishery' or 'fishing-town' (Eiselen, 1907) as Sidon is known to be the third-largest city in Lebanon. It is located in the South Governorate of Lebanon, on the Mediterranean coast. Sidon 'was once an important Phoenician commercial city which saw the shift of various rulers such as the Egyptians, Assyrians and Persians, and was since 64 B.C. part of the Roman Empire. The city had been the seat of a bishop. However, from these periods onwards as well as 
from the first centuries of Islamic rule (Umayyad, Abbasid, Tulunid, Fatimid, and Saljuq), no remains are visible in the city. They are to be found buried under many layers of present-day structures, especially at the site of land castle. The oldest remains, the sea castle, date back to Crusader period." (Weber, 2003).

It is relevant to explicate that the city "is, in its present historical structure, a more or less pure Ottoman city" as the most impressive building of that time, the Khan al-Franj, "was founded around 1560 by the famous Ottoman politician Sokollu Mehmed Pasha". During "the first half of the $18^{\text {th }}$ century the Hammuds played a central role in the city and constructed several outstanding monuments." "Qasr Debbane in Saida", "one of the most crucial historical monuments on the Lebanese coast and was recorded as an historical monument in 1968. Founded in 1134/1721-22 as a palace of a local notable, a certain 'Ali Agha Hammud, it reflects the history of Lebanon over the last three centuries. The Debbane family bought this house probably in the early 19th century and renovated it in the early 20th century, keeping up with the latest fashion of the day." "The houses of "Ali Agha (Debbane) and Ahmed Agha (Madrasat A'isha) as well as the Khan al-Hummus (Qishla) were built partially". (Weber, 2003) See Figure 1.

Historical town centres like Sidon 'in the Arab world are in urgent need of a reevaluation, and only intense efforts of the local communities can save them from decay' The Lebanese Civil War and the threads of economic and social crises in this Middle Eastern country have turned the historical cities like Sidon from outstanding and iconic centres into civic disorder.

Indeed there is an economic challenge throughout the city's transformation at the present state. The souks around the historical buildings 'have ceased to be a pole of attraction', 'which is limited with the absence of its artisanal workforce. The social is in state of loss in its cultural diversity and mix. Image is unattractive from the outside. This provision is, of course, the result of historical, spatial and social processes, old and recent, but which is likely to become stronger under the pressure of the economic, social and real estate recomposition. This situation calls for work on the integration of spaces and communities and a certain social mix, to achieve a space of cohesion and exchange', by this the composition of modular pattern and its prolongation over the city's grid as norms found intact with the historical context are being projected further over the void found with the absence of historical buildings due to their destruction and communal neglect. (Lebanese University, 2003).

The 'patterns that one frequently finds in Saida', which have been validated by this paper, 'were partly exact copies or parallels of those frequently used patterns in Damascus. On older buildings in Saida or Dayr al-Qamar this style and these techniques were not applied and it is obvious that upper class families in southern Syria and 
Lebanon during the $17^{\text {th }}$ and $18^{\text {th }}$ centuries turned towards the regional centre which was Damascus' (Weber, 2003).

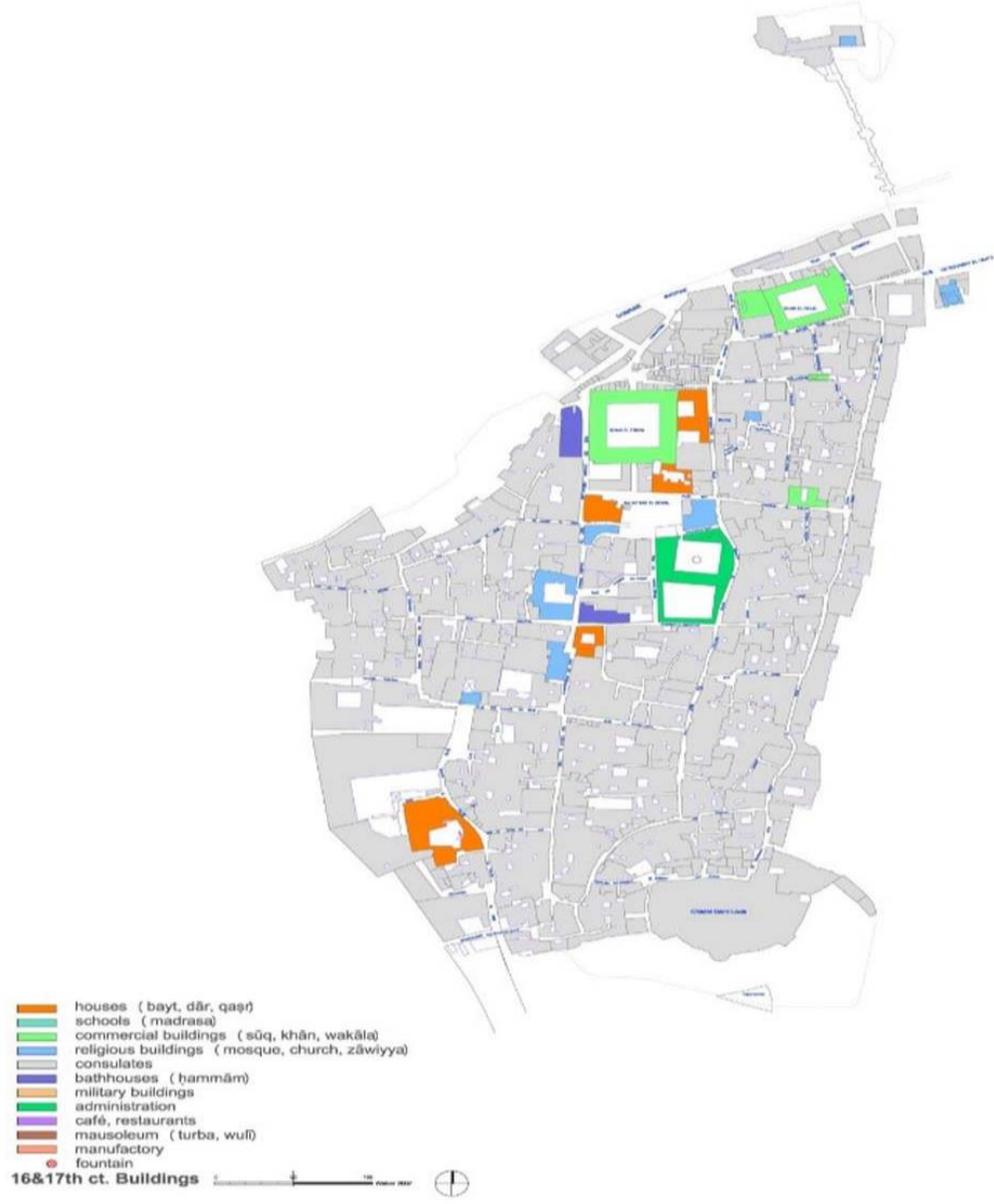

Figure 1. Sidon's buildings in the $16^{\text {th }}$ and $17^{\text {th }}$ centuries highlighted (Weber, 2007).

The 'Damascene House commonly known at the age of A'yan (notables), the period from 1695 to $1831 / 1839$ saw a great boom in large-scale construction. Governors, notables and great families (the Cheb at Hasbaya, the Azem in Syria, and the Hamoud at Saida ...) had hammams, khans, and especially large houses built. The architectural style of this time has been an evolution in the elements of the second half of the 16th and especially an index of the Ottoman impact on the local architecture. The damascene house illustrates this style with excellence.' (Lebanese University, 2003).

'Regarding the q'aa: characteristic piece; the great Damascene houses have had many pieces that are differentiated and called -iwan, qa'a, murabbaa, qasr, tayyara, etc.- 
according to their use or their spatial qualities. The two most characteristic rooms of the house are iwan and qa'a; the small houses are generally deprived of them'.

By regularity and in their definitions the iwan is a square-shaped summer living room located on the ground floor: it develops on a double height and is fully open on the courtyard by a broken arch; it is normally oriented to the north. While the Qa'a is a large reception room; it includes an ataba and one or more tazar. Everything differentiates these two spaces, the ataba is paved, can have a fountain; it is through her that one enters the qa'a, one leaves his shoes there before going up in the tazar which is higher of about forty centimeters and separated from the ataba by a stone arch. The floor of the tazar is covered with carpets; the walls are covered with woodwork up to half height'. (Lebanese University, 2003).

The damascene house does not lack elements and decorative techniques on the contrary the "colour paste" technique developed in Cairo and Damascus in the 14th and 15 th centuries was exclusively damascene in the 16th century, incorporating Ottoman floral motifs such as the tulip flower. The mouqarnass, the ablaq (altered two-colored waist stones), the fountains, the tiles, joinery and ironwork, the various examples presented reveal the richness of the "Damascene house" and the diversity of the modes of association of its ensembles.

Back to this paper's hypothetical substance, it is in the morphological and architectural nomads encountered within the Ottoman Houses and Khans which are extremely important to be studied specifically the modular patterns that are bestowed in each of the building elements where the reference can be also given to the climate as one of the challenges amid the mild, temperatures ranging in January and rain falls mostly in winter while humidity rises during summer months. The provisions of measures historically presented were to prevent the total collapse of the parts of the building and its surroundings. The construction using local materials was in the part that brought the building to its former state using the local crafts of the region.

The buildings were almost entirely constructed with sandstone and a mortar consisting of lime and sand. Some Ottoman works reveal the use of "black pan mortar", made of lime, mud and ash, especially utilized against humidity. Limestone was used as infill material.

All the building materials were local and ashes (from burning lime) were brought from villages nearby. Few large pieces such as lintels and drain spouts were made out of stone, worked with a hammer and chisel. As for the techniques they were entirely traditional techniques employed for the reconstruction of collapsed walls, arches, vaults and domes. 
By emphasizing such a recurrence in the nomads of Sidon's building of houses and Khans we could set the framework by which the obstructed could be outlined since there were no records on their interiors, hence their functional and spatial setting could be derived from the Ottoman Houses that share the same spatial definitions by prolonging the historic textile over the site. In other words, the size and pattern type of modules found are protracted over the restoration strategy made after discovering the prototypes used by the builders of the Houses and Palaces in addition to the Khans of the city.

Due to the construction of the coastal road in Sidon, the remains of historical structures were buried underneath the road strip; hence it was difficult to trace the foundation for those buildings as the House foundation is now submerged underneath the asphalt road. The data had to be collected by which meetings with various authorities were held, following which a 3D laser survey of the ruins was conducted with immense accuracy of the mapping imprints for the fragments of buildings The innovative laser survey could to an advanced extent substitute the custom methods of classical examination tools and substitute to a large magnitude the cadastral maps.

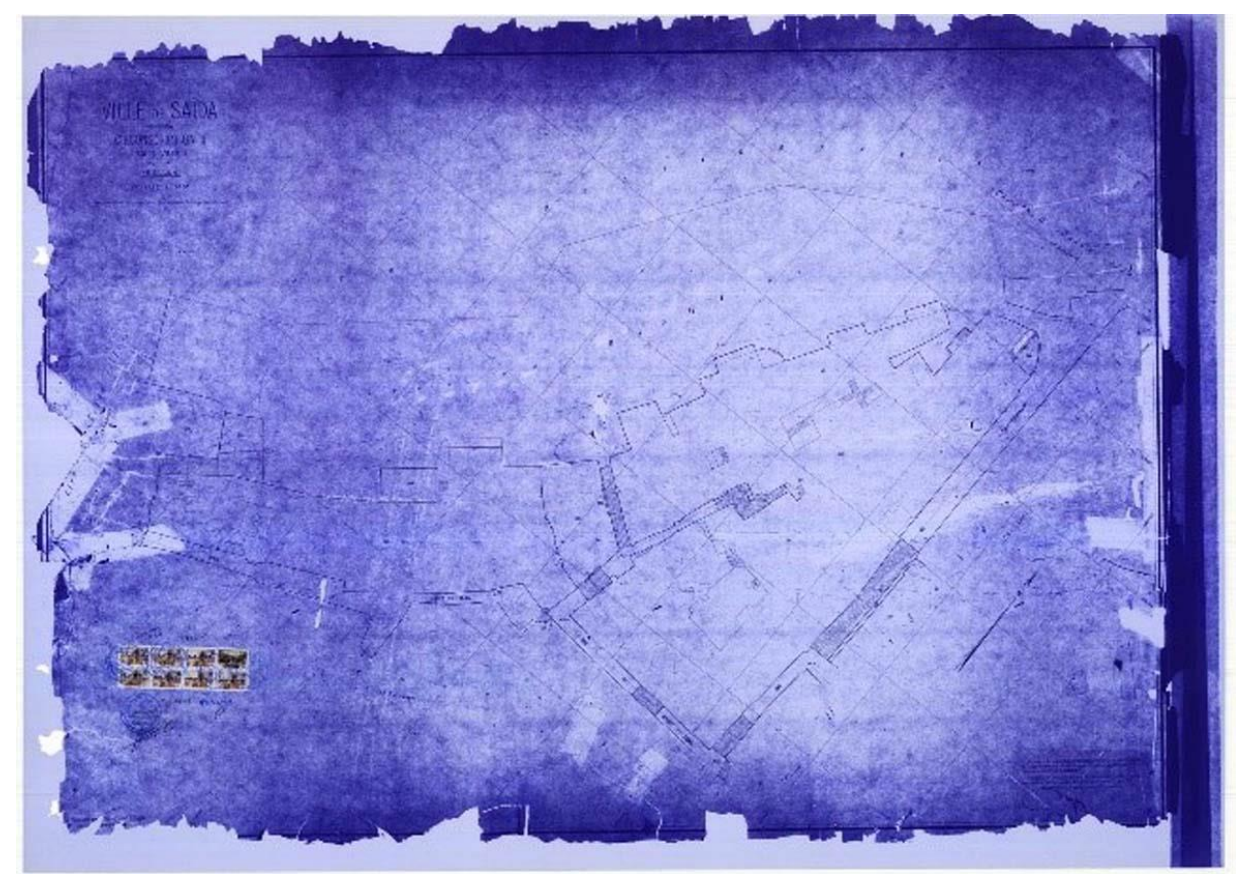

Figure 2. Cadastral Plan of Sidon (Weber).

A local company named GSS (General Surveying Services) was hired as they have used FARO 3D Laser Scanner for every building at the location and the 
surroundings by which they provided a Point Cloud' as well as 3D imagery of the area, which enabled us to measure the dimensions of any feature in the façade, void and along the corridor of the road.

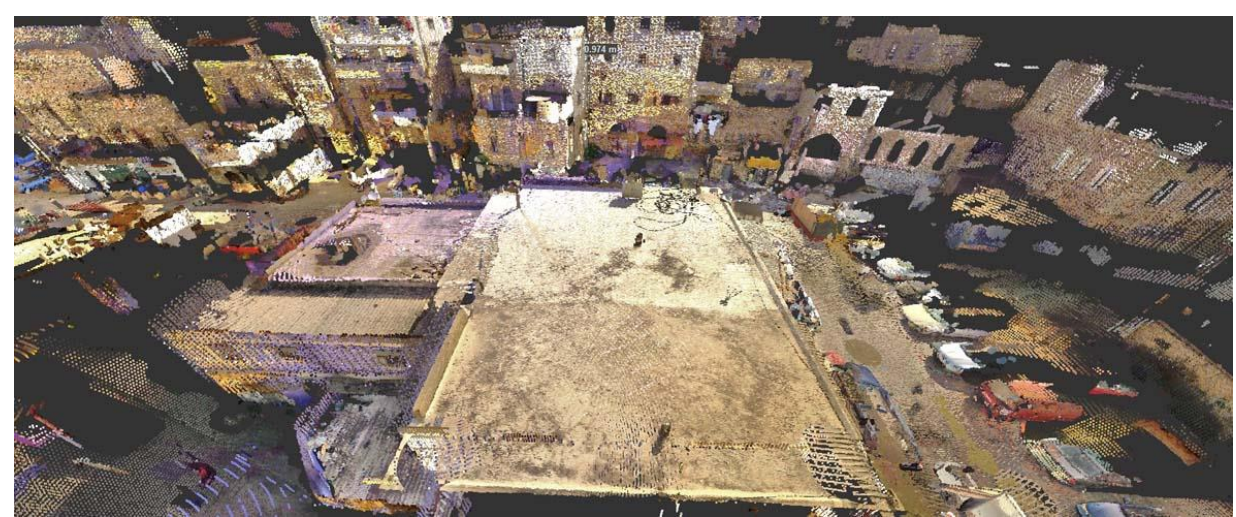

Figure 3. Image of the scan (GSS \& Author, 2016).

The above data allowed us to retrace the absent parts and establish the exact location of the missing buildings as it came to mind that if we developed a technique that employed an integrated outline to map and match existing buildings throughout Sidon and in imposing such a finding on the missing layout of the buildings to be restored will surely recover the missing structures by creating spatial syntax made of repetitive patterns throughout the city, and this is done in order to verify the verdict taken in the process. In which in this paper's case the pixels with modular dimensions of 5 meters could be detected in so many places in Sidon.

The encountered monotony according to this paper's analysis is due to structural and architectural norms that were inhabited in the Houses and Khans of an era of dogmatic ingenuity of the Ottomans, by which their norms flourished in the region and their buildings were drawn as templates that occupied one city to another.

By overlaying the above module on the survey, we found a clear composition between space and function. This helped us in not only understanding the building remains but also in defining strategies for rehabilitation - we will elaborate this more in the section of Sidon's Typology.

We have continued to map the fine details and patterns throughout Sidon. We have checked the architectural integration as well as the social, environmental, and other sustainability aspects to determine which floor layout is most appropriate for finalising the geometry and structure of the proposed restoration. 
As modular repetitiveness throughout the Ottoman Empire was is an ideal method of construction as it eliminates the necessity for excessive architectural details. The way the buildings were built constitute a responsive policy on how to attain a nonwaste design by not nesting any exploitable space, which is the case with Ottoman architecture as it elucidates the need for extreme precision, and the necessity for a highly precise arrangement of building masses. (Ghoussayni et al, 2018).

With regards to the local grids, Dr 'Davie refers to Roman times of Beirut and its grid street pattern that was aligned on cardo decumanus' (Ozturk, 2006), 'the gridiron plan could not be fully trailed in the nineteenth century' (Davie 2006). This communes to our mutual understanding that grid pattern was also envisioned in Ancient cities like Beirut.

\section{METHODOLOGY}

The method used to acquire the modular findings is based on the knowledge of Sidon's entanglement with historical norms of building manner, such as the city's heritage of old souks and Ottoman-built structures with layers of modularity that we have found in some Ottoman houses. We could determine from the cadastral maps the technique of distinguishing between demolished and existing structures.

We also must completely understand the historical spatial designation exhibited in the profound modular patterns and use them to determine the best practices for rehabilitating coastal Houses and buildings that were destructed. In order to trace back the interiors of the Houses that will be restored, we could be guided by many factors, one is by looking at the Image in figure 4.0 where the facades could be detected as in their original condition before they were ruined, second we could make use of old surveys made in this regard for Sidon by the Lebanese University and third we may refer to the Cadastral Maps.

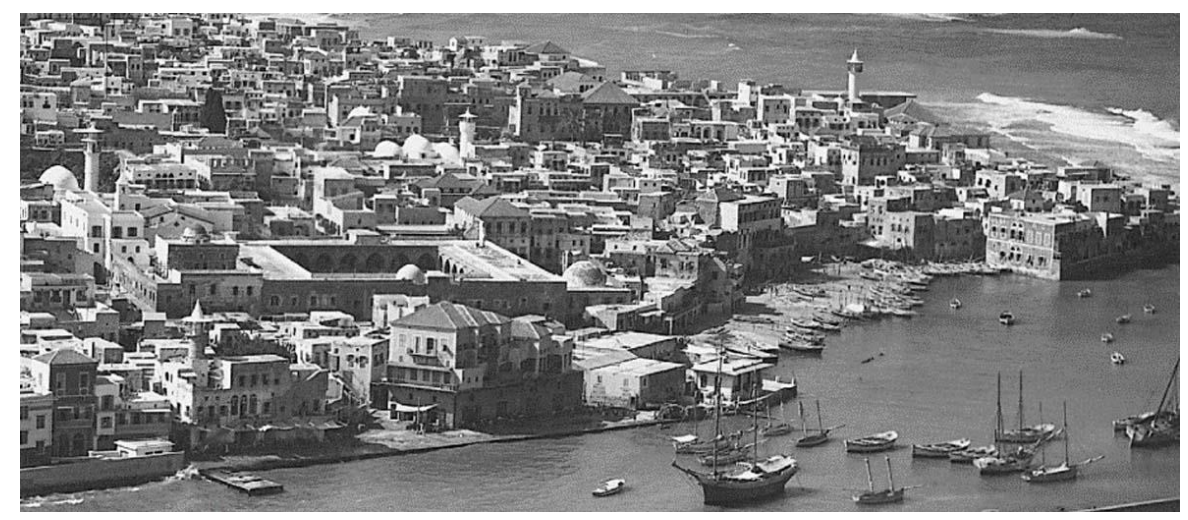

Figure 4. Image, 1977 (Weber). 
The modular patterns have existed in the Ottoman and late $19^{\text {th }}$ and early $20^{\text {th }}$ centuries, when Sidon was at its peak. These patterns emerged from various kinds of historic buildings, and have been documented through the current survey by referencing old cadastral maps as well.

This paper proposes visual representation along the relationship between Sidonians and their lost historical structures by using a layer showing the link between the city in its current condition and the sea.

Through this study, we deduced that the dilapidated buildings, some of them dating to late nineteenth century, are likely to have regarded traditional patterns from Ottoman architecture, by which they would revealed socio-spatial practices similar to the city's unique inheritance. This paper also addresses memory that is deeply rooted in these symbols of the past and the 'level of consciousness toward the sensorial experience in the built environment should be primary' (Bencivengo, 2012).

These old arrangements of customs use are found as-spatial practices of houses and Khans which were attributed by the local architectural palette of the region.

\section{Theory and Principles}

By understanding the principles of modular patterns, we created a language to visualize the space of Sidon by using basic units, known as pixels, with a module of 5 metres. The basic spatial dimensions, such as between two historical buildings, may vary in time and location but lead to the same pixel arrangement that resembles spacevoid patterns of the city's morphology.

'What we call now the 'overall pattern language approach' in architecture, urban design, and planning has grown from its original principle of 'pattern and pattern language' into a large and solid body of theory and professional work'. (Neis, Joachim, Baumgartner, 2015)

'The idea of a pattern in this specific understanding is first based on the observation of repetition of particular building elements' such as the Qa'a, typology, function, colour, material, structural methodology 'which form substantial knowledge of a building culture or culture in general. Hundreds of these patterns may define the building knowledge of a given culture, and thousands might describe close to the overall cultural knowledge of a given culture' (Neis, Joachim, Baumgartner, 2015). 
'The importance of using a Pattern Language is that it combines all of the different visions and needs of the people involved into a common language that everyone can understand. The simplest form of applying a pattern language to a given design project - for example a residence - is to select a set of patterns and use these solution-patterns as archetypal starting points for a design and building process'. (Neis, Joachim, Baumgartner, 2015)

Since patterns and modules are simple in construction which drive architects to use them in almost all building elements, from ornaments to spaces as they 'focused more extensively on other aspects of architecture, such as form and master planning.' (Abdullahi, 2013)

With regards to the Typology and restoration techniques, the cultural landmarks are historical products of society and its activity within places, and constitute collective identity in continual transformation throughout ages. The historic city of Sidon responds in a general way to the rules of an Arab-Muslim urbanism and privileging the opposition between the public space and the private space. Indeed, it is organized mainly around two networks. The first network brings together most of the public spaces along the axes: souks, hammams, madrassas, mosques, cafes, etc. (Lebanese University, 2003)

This is clearly depicted in the pixilation of void that distinctively prevails in the series of private space versus the public domain that can only be portrayed over the overall setting and cluster composition throughout the city. The space where networks are chained into the culture and every day's tradition among the narrow and dark alleys and open air spaces that separate the blank interior, the private, from outside, the public. See figure 5 and figure 6.

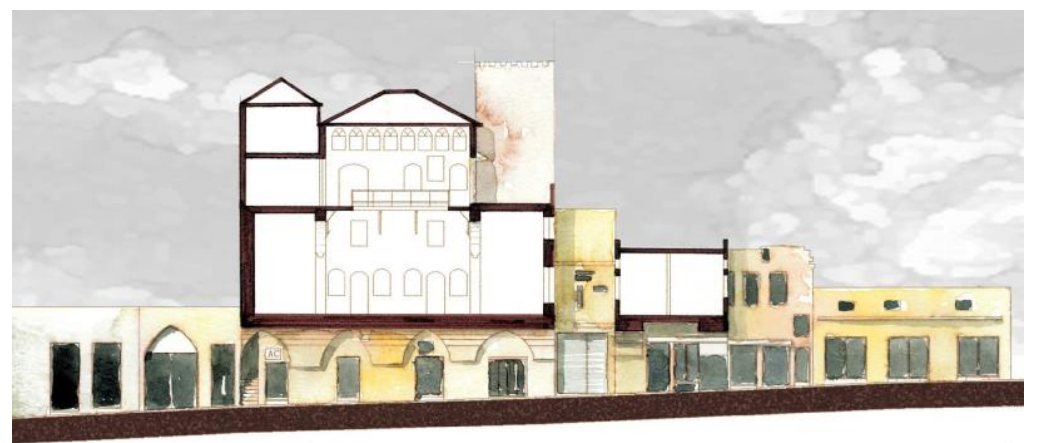

Figure 5. Elevations and Typology of Sidon (Lebanese University, 2003). 


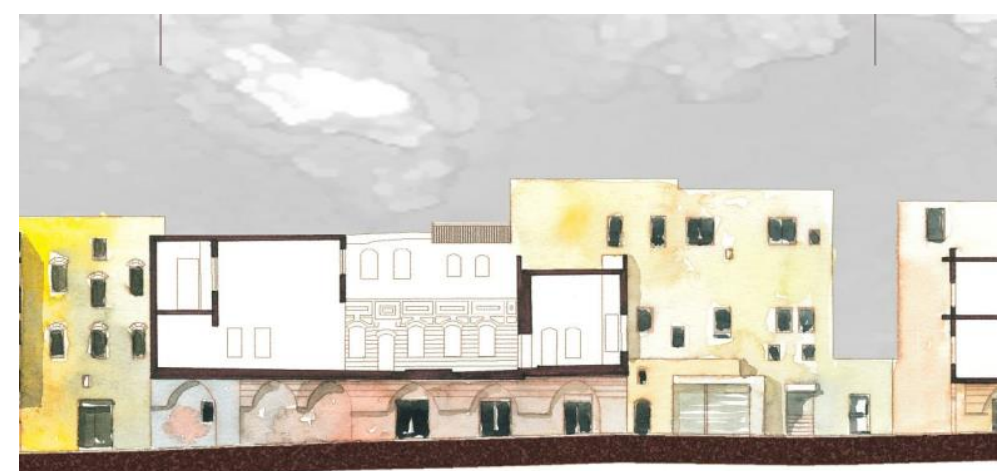

Figure 6. Elevations and Typology of Sidon (Lebanese University, 2003).

"This analysis while based on the relationships between the elements of the urban form with history and the activities they supervise, are nonetheless economic, social, and patrimonial issues of the old city". (Lebanese University, 2003).

The city, already densely occupied, was divided into quarters like a pattern like attribution of different trading communities. The first French scale of the Levant is another additive to the cluster of unit enjoyed with a period of prosperity, which is reflected in the creation of warehouses and soap factories. The city under the Ottoman Empire did undergo in great changes out of its historical limits.

Regarding the common typology of openings it is very difficult to draw up an exhaustive "inventory" of typologies encountered in the city. As a result of the changes that have affected the urban fabric, new forms of openings have emerged and brought into place. See Figure below which presents the different common typologies. By this we could do similar approach to the restored buildings by which we could implement similar typology. See figure 7, figure 8, figure 9 and figure 10.

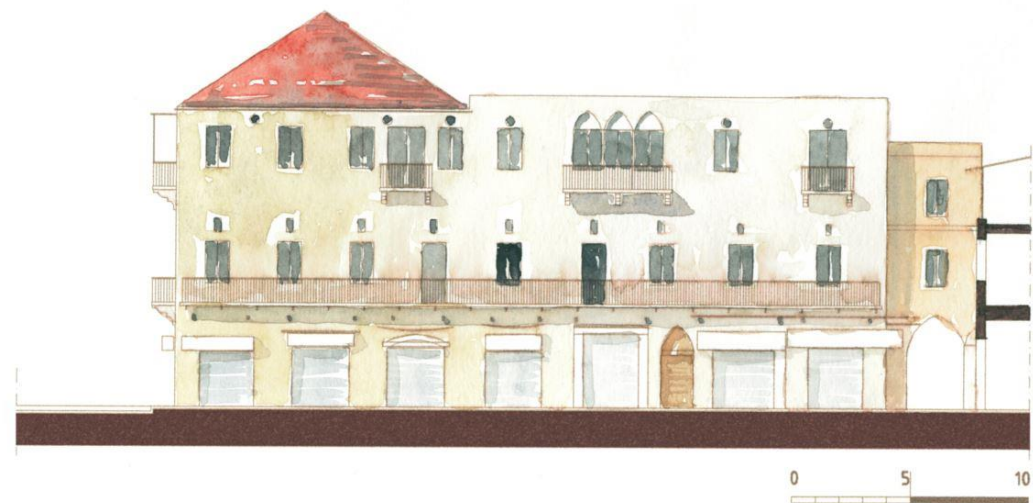

Figure 7. Elevations and Typology of Sidon (Lebanese University, 2003). 


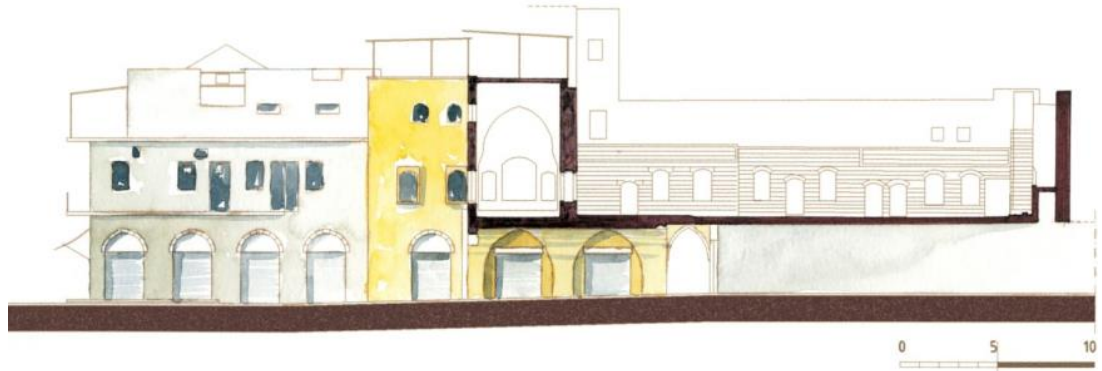

Figure 8. Elevations and Typology of Sidon (Lebanese University, 2003).

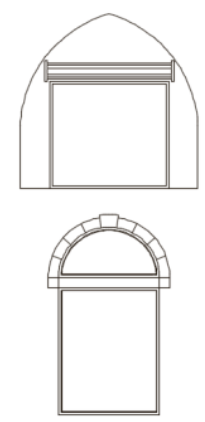

(a)
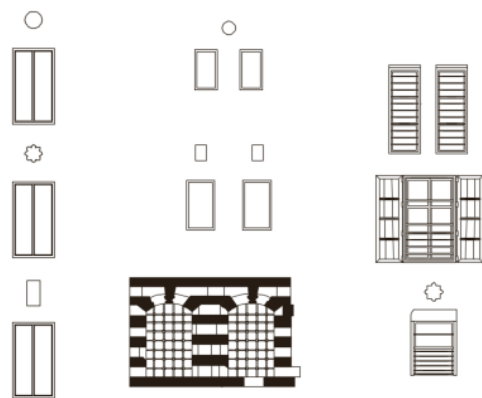

Figure 9. (a) Commercial Door Opening, (b) house window opening (Lebanese University, 2003).

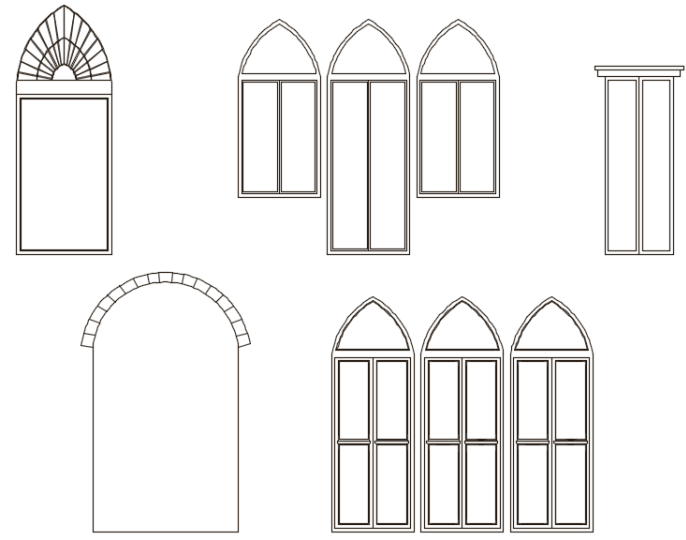

Figure 10. House door opening (Lebanese University, 2003).

"The dominant typology of domestic architecture in Sidon is best represented by previous stated examples as what characterizes, particularly, the architecture of these houses, morphologically is their internal organization around the court, their inclusion in the souk, their contiguity to the neighbours, their interweaving in the public space 
and their modest access and narrow in contrast to their rich interior, according to the Arab tradition in the dwelling whose interior had more importance than the outside. The ground floor of these houses usually accommodated small shops, a barn and sometimes a garden. The dwelling and the dwelling proper are on the first floor". (Lebanese University, 2003) See figure 11.

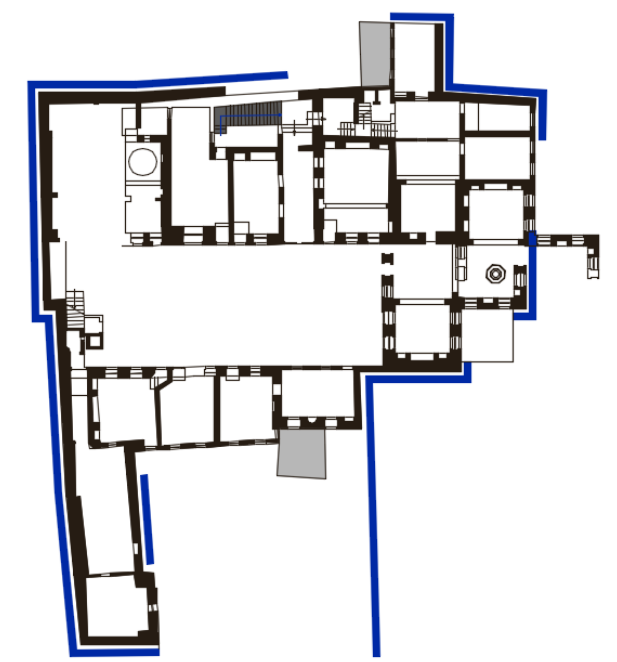

Figure 11. (Bayt Hammoud) Less than $30 \%$ of the total perimeters of the facades is perceptible on the side of the souks (Lebanese University, 2003).

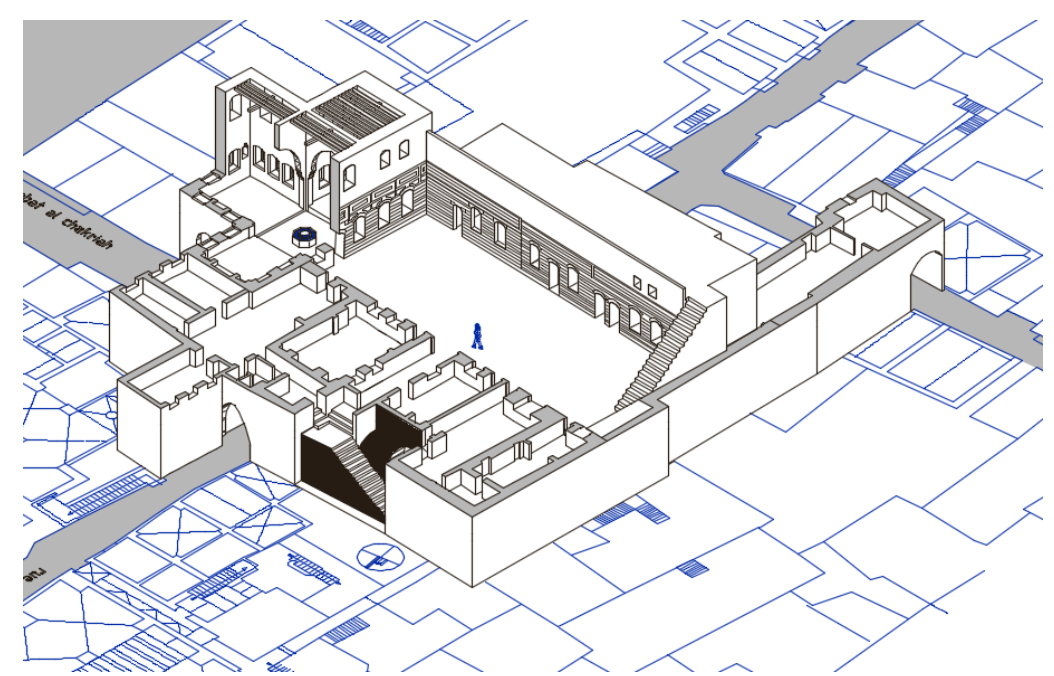

Figure 12. Axonometric, showing Dar Hammoud (Lebanese University, 2003). 


\section{Overlaying the Map of Patterns}

In this section, this paper shows how a grid is set over the surveyed historic architecture of Sidon Buildings.

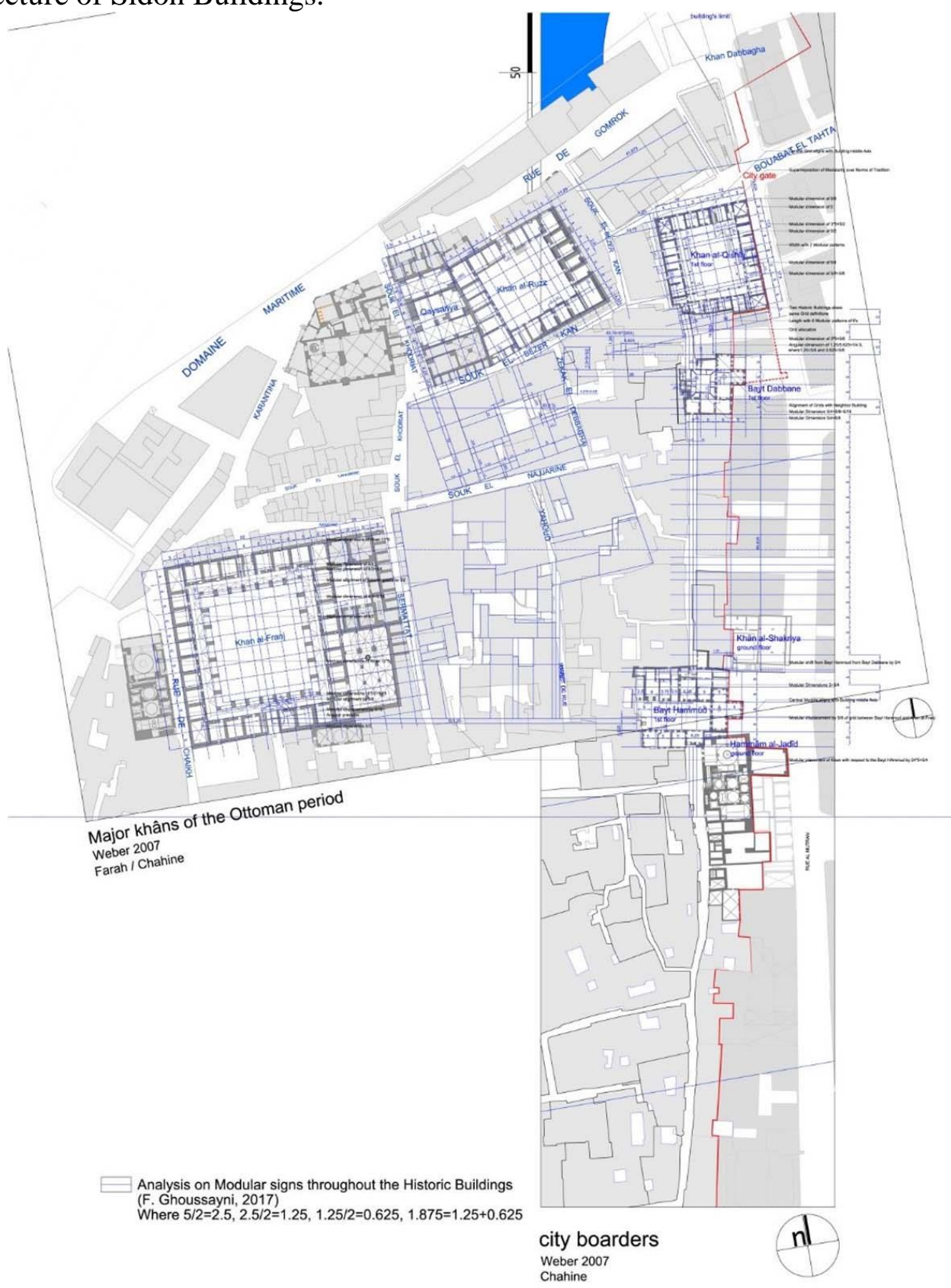

Figure 13. Analysis of modular signs in the historic buildings of Sidon (Author). 


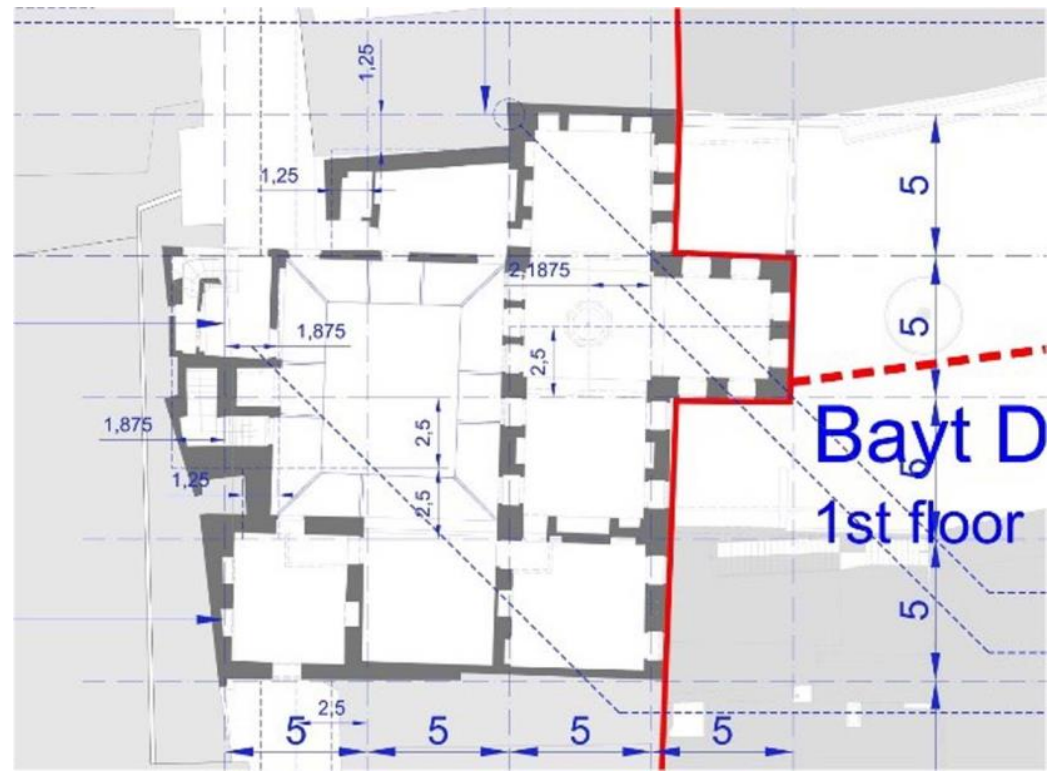

Figure 14. Analysis of modular signs in Bayt Debbaneh (Author).

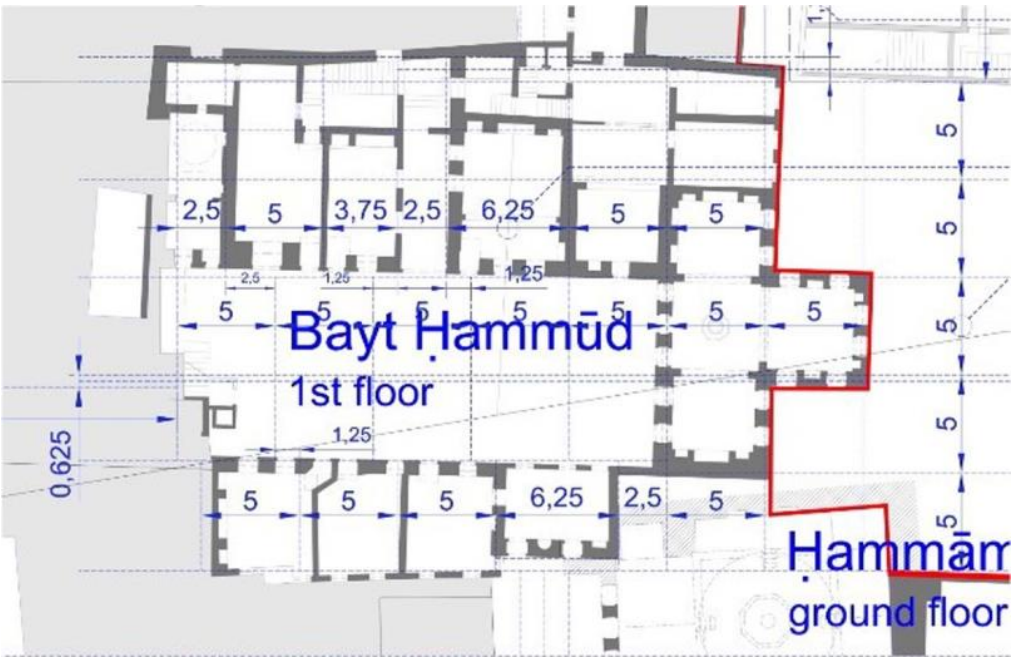

Figure 15. Analysis on modular signs in Bayt Hammud (Lebanese University, 2003) (Visualization by Author).

A simulation is set over the coordinated values using the survey plan for the Khan and its surrounding area, we have assured this paper's finding of several repetitive patterns in multiples of girds of 5 meters inside the listed building plan.

There are numerous sophisticated patterns that appear in the interiors of buildings, such as the ornamentation inside the house of Bayt Hammud. We believe that the Ottomans intentionally embedded their architectural signature in the structures they 
built in order to parade their norms of solidarity and cohesiveness throughout the empire.

The typology above seems to have been a common practice in Ottoman architecture.

\section{The Context Analysis}

There is an association between Ottoman architecture and the modular patterns that it contains as it is pertinent to ascribe Sidon's entanglement to powerful aspects of political and social cohesiveness affecting the Western coast of Lebanon. After the arrival of the Ottomans in 1516, the change happened 'as it seems, after the middle of the $16^{\text {th }}$ century. Saida was not anymore on the uncertain border of the empire but as Ottoman port city laying on one of the main communication lines of the empire: the Mediterranean. Saida became the main harbour city of Southern Syria and was literally rebuilt. This seemed to be a conscious reinforcement of the eastern Mediterranean trade routes' (Weber, 2003).

Some of the historical buildings reveal a construction grid by which they were built specifically those under the Ottomans. See figure 4.0 for the visual appealing of buildings in the place of this study.

Through this survey we could highlight buildings that no longer exist to differentiate them from those that are shown on the cadastral maps (see Figure 16.0). We used this information to focus to define the appearance of buildings and space versus the void which was created when the historical buildings were destroyed. See Fig 16.0

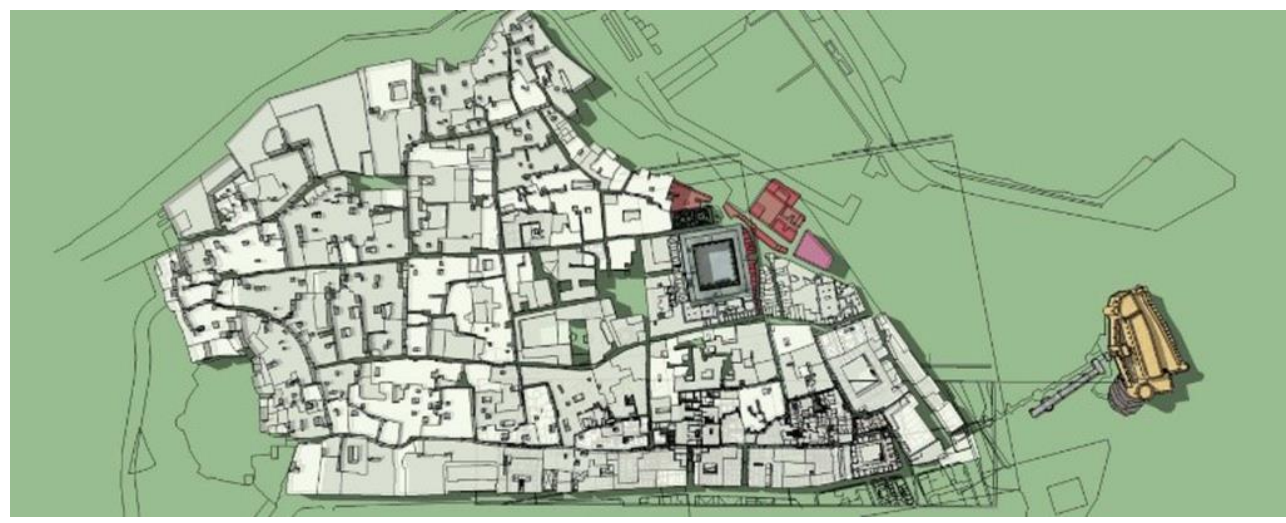

Figure 16. Destroyed buildings depicted in red (Author). 
'Each pattern is a field-not fixed, but a bundle of relationships, capable of being different each time that it occurs, yet deep enough to bestow life wherever it occurs' (Alexander, 1979). Like an arc within a house or a bridge above a souk using modest tools with modular arrangement of components and which necessitate an understanding of the materials in hand that are associated to a specific environment and available resources wherever it occurs.

It is very clear the rupture 'from the Sea Front' and rupture 'from surrounding areas' by which the solution would be to stitch back the raptured part with the Mediterranean Sea. (Al-Harithy, 2013) As in 'Sidon, pollution has spread all along the coastline' (FIDH 2006) due to the interface of coastal road and its association with sewage pipelines in the area which could be diminished if the road was deviated like we are proposing and the infra would be elevated to a clear isolated platform away from the sea front and stitch back the part that was lost.

At this stage the paper is more inclined to bring together 'a code, like the genetic code, for human acts of building', as it 'takes the form of language' (Alexander, 1979) like the void of Qa'a or a courtyard where the Arab courtyard house was developed in order to guarantee concentrated privacy out from the public domain by excluding any street-facing façades and by concentrating its entire splendour into the interior. This is in accordance with what we found in each of the buildings that will be listed below. See Fig 17.0 'This is the case with the Qasr Debbane, where the courtyard is located above the main suq of the city. Privacy seems thus to have been even more guaranteed' (Weber, 2003). See figure 18.

In figure 17 we have highlighted the repetitive patterns of spaces by a value of $5 \mathrm{~m}$, their depiction of similar arrangements with other buildings holds a code that spaces used to be designed by architects' tools and pallet of the region were being recurred. 

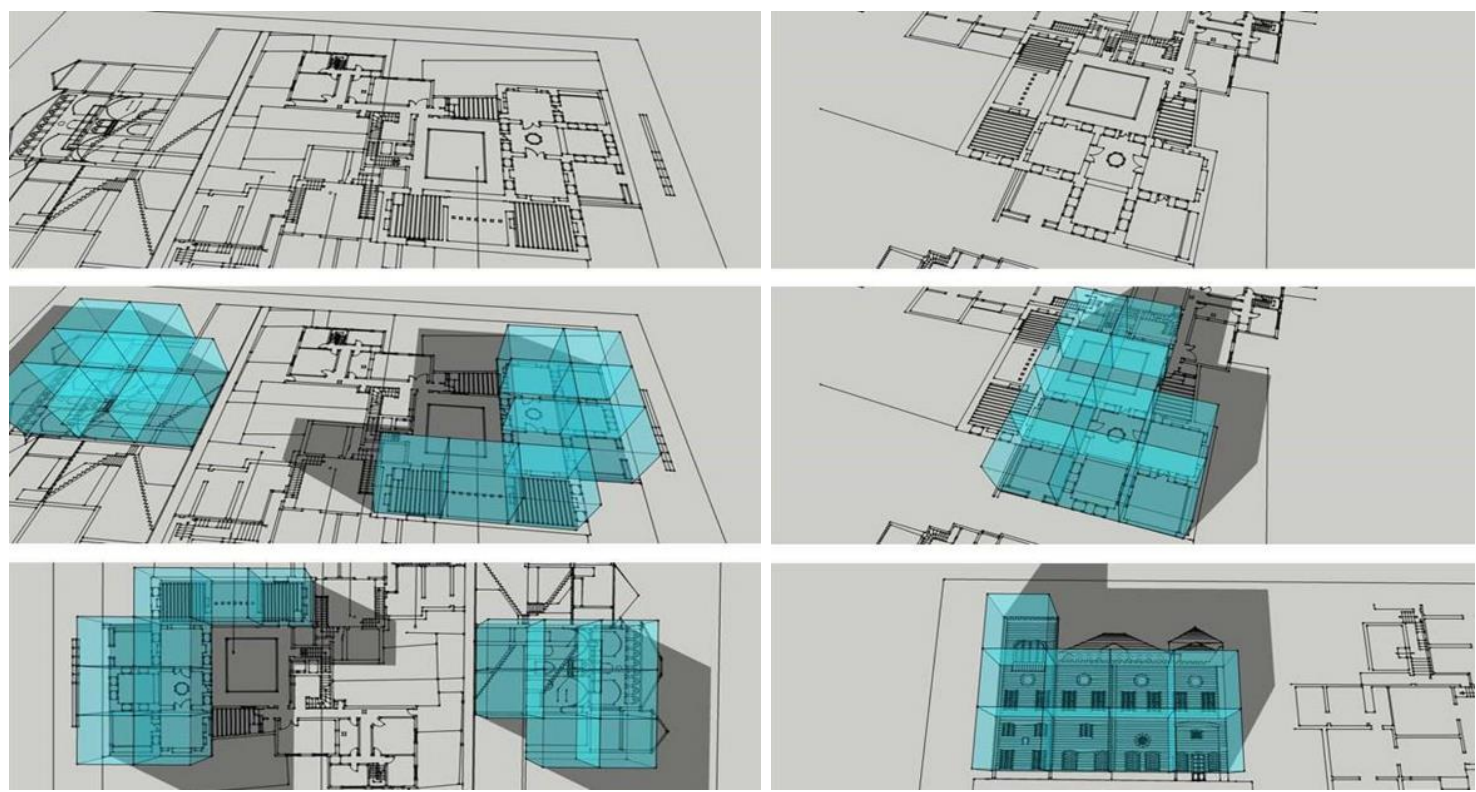

Figure 17. Modules in House of Sassy.

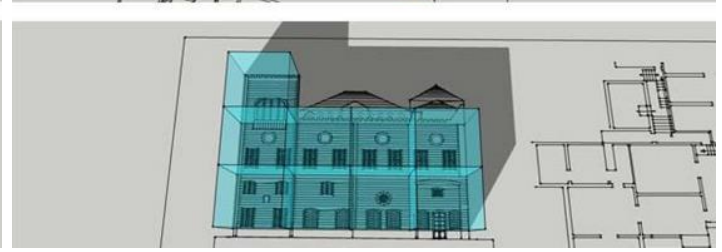

Figure 18. Modules in Debbane (Author).

In figure 19 we are also highlighting the spatial repetitiveness of modular dimension of 5 meters within the interiors of spaces in Bayt Hammoud similar to other historic buildings in the neighbourhood. It is to be noted that the Hariri Foundation did the Rehabilitation of the Hammoud Palace (Madrasat Aisha) and in association with Foundation Saida's Heritage and Environment Association.
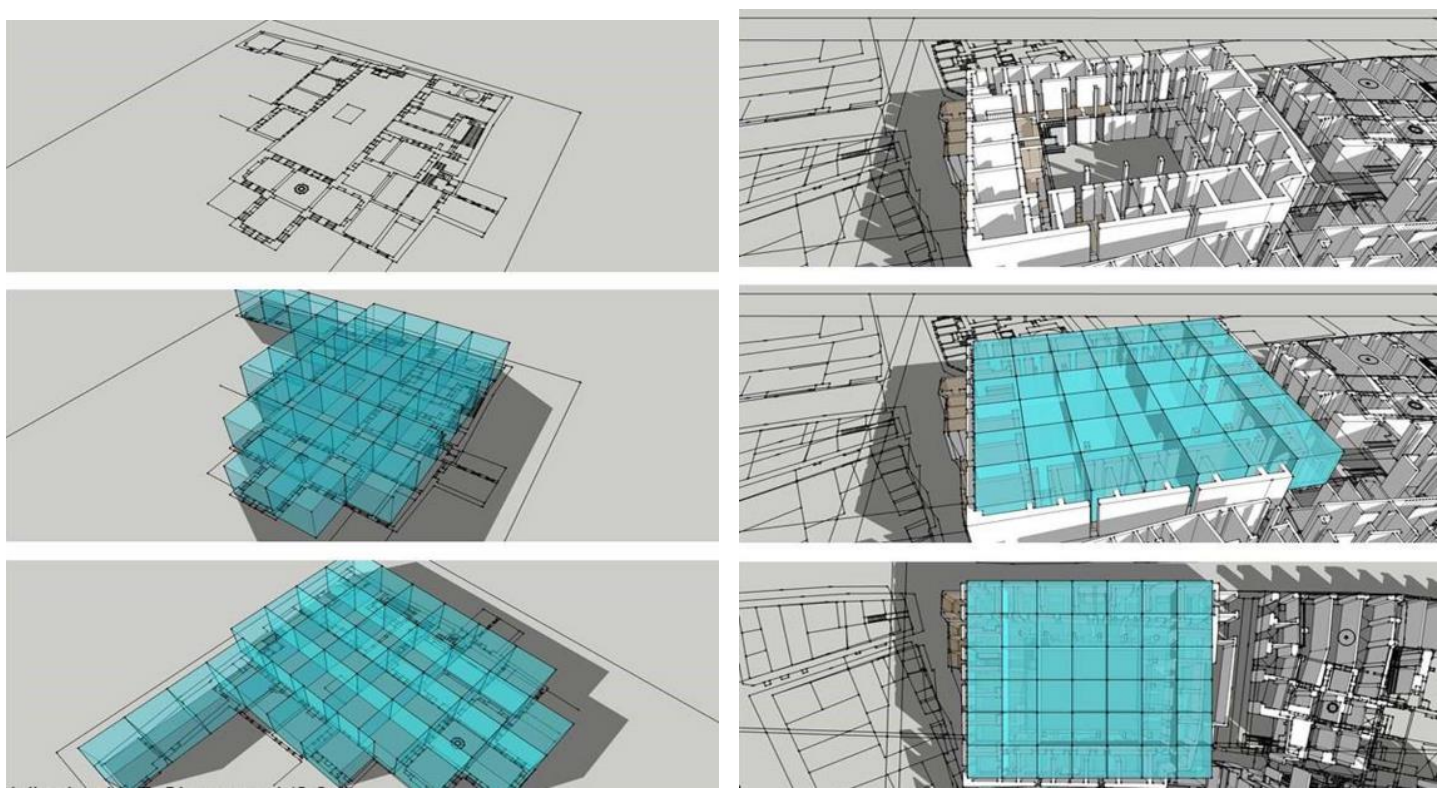

Figure 19. Patterns in House Hammoud

Figure 20. Al Share Street (Author). 
As demonstrated by the findings depicted in the figures above (see figure 19 and figure 20), it shows that the buildings appear to be portraying a modular repetitiveness. This paper by setts the overall dimension of $5 \mathrm{~m}$ by $5 \mathrm{~m}$ and overlays it on the interior of space within the destructed buildings, by this we would have captured the structural grid that would be set according to and in addition to the size of the interior spaces per each room, starting with the court and moving ahead with the remaining rooms.

In the figures below, this paper further clarifies findings of modular and spatial recognition conducted throughout the old city of Sidon.

The function and utilities in the historic centre of Sidon will be superimposed over the layout of the city in pixelated display.

This paper was able to trace some orthogonal alignments in the streets of the old city, accompanied by alterations in some other areas. However, the figure below, to some extent, draws the hidden grids of building's clusters and general morphology of the urban fabric. There is no doubt that we can draw (in red) as in figure 21 the cluster of buildings. The pixelated depiction of a modular grid of $5 \mathrm{~m}$ sets a suitable balance required in the direction of the destructed filaments (see figure 22) in order to create a grand pixel of settlement, considering the depth and weight of buildings derived from their historic and elemental significance. It is clearly depicted that most of the important pixels lie on the coastal curvature (see figure 22) but are still lacking the connectivity with the Mediterranean Sea. Therefore, the proposed link would be clearly shown in the figures below. By this we extend the module into the location of the obstructed buildings. 


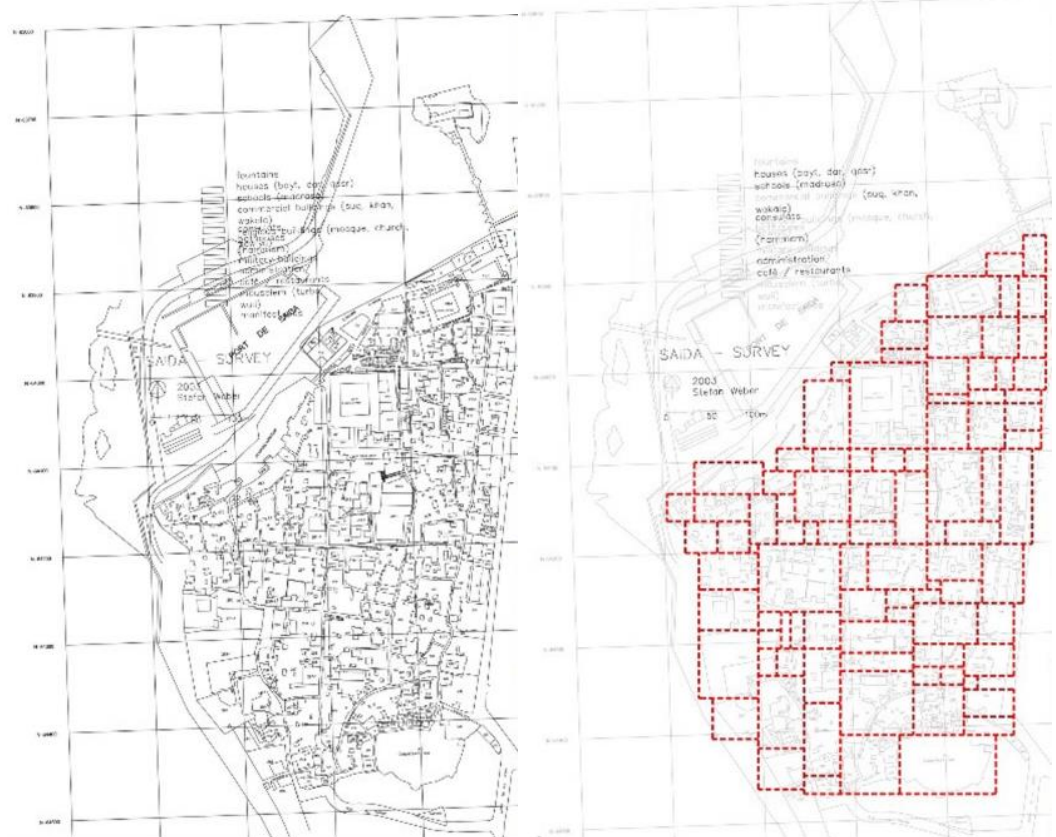

Figure 21. On the left: Old city map (Weber); On the right: Map of interchanging modules among building clusters, internal roads, and routes, in multiples of $5 \mathrm{~m}$ as partitioned by the internal streets (Author).
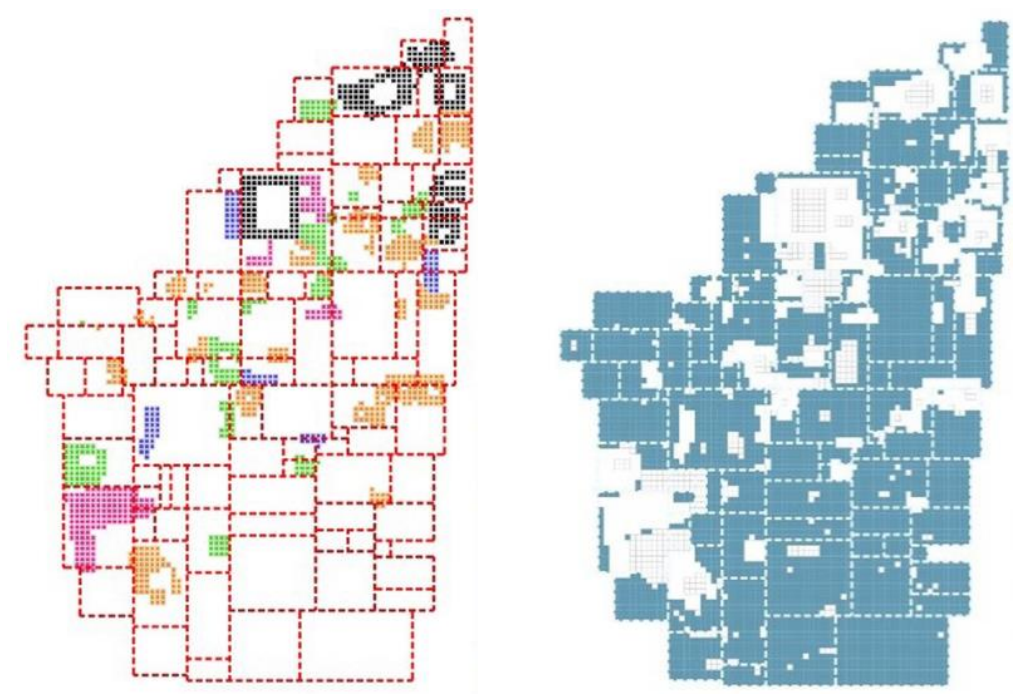

Figure 22. On the left: A pixelated and coloured representation of functions amid the uneven distribution of commercial and historic buildings (Author). On the right: Distribution of historic buildings depicted in white versus ordinary buildings in tinted blue (Author). 


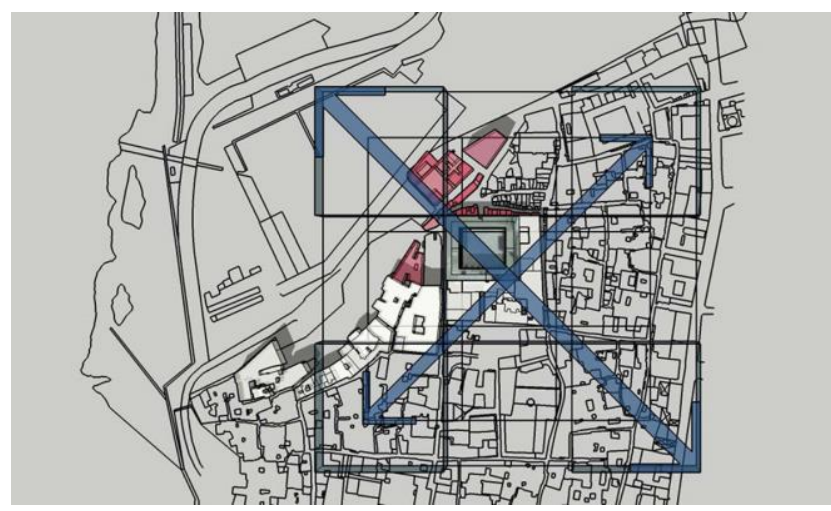

Figure 23. Proposed future orientation in the direction of the red allocation of historic buildings that were demolished (Author).

This paper's findings would not have been illustrated clearly if it had not been true that the 'most characteristic technique of a local style' are 'consisting of elements from the architecture of Damascus before the Ottomans on the one hand, and from the single but strong impact of Ottoman architecture during the $16^{\text {th }}$ century on the other hand' (Weber, 2003).

The below visualization of the obstructed buildings from Fig. 24.0 to Fig. 26.0 are the result in this paper's pursuit for modularity of patterns.

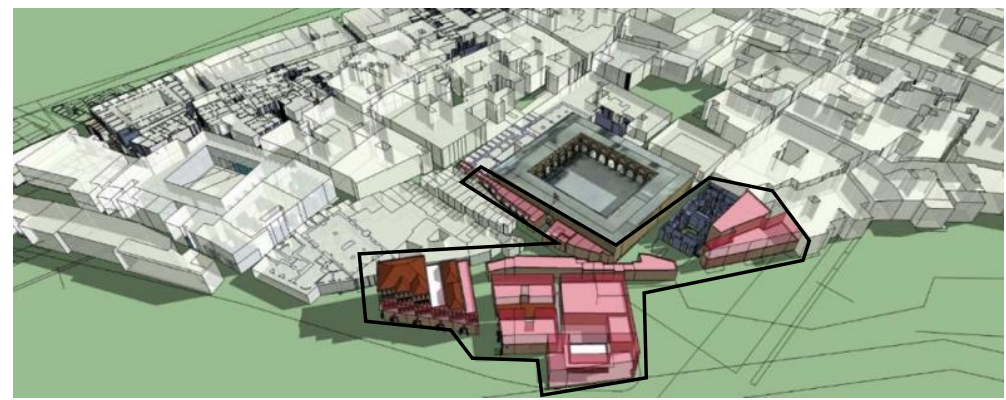

Figure 24. Visualization of the obstructed buildings and the void (Author).

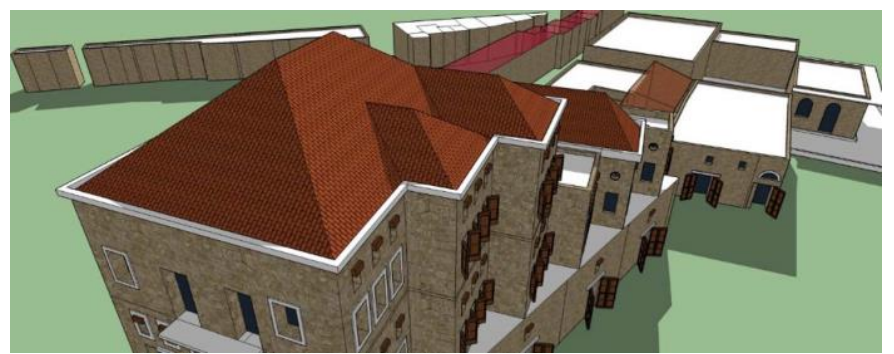

Figure 25. Visualization of the obstructed buildings (Author). 


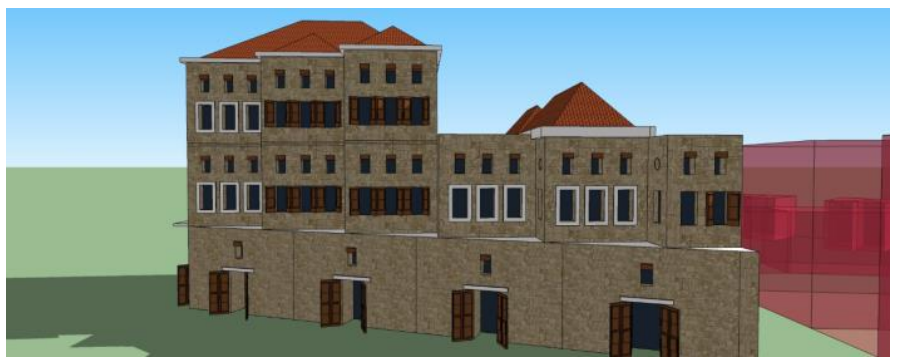

Figure 26. Visualization of the obstructed buildings (Author).

In Figure 27.0 this paper shows the ideal outcome from previous stated methodology and patterns findings, as now the interior could be determined and drawn.

Figure 27. Final plan of one of the obstructed houses as conceived from Modular configurations (Author).

\section{CONCLUSION}

The aim of this study was to gather data from historical ruins in the city of Sidon by using methodological norms and propose a method for rehabilitation and renovation of these buildings using modular patterns. We believe that this study makes a significant contribution to the literature because, using the data from this study, we have been able to arrive at the best way the ruins of Sidon can be rehabilitated in a way that accommodates urban development. Further, we believe that it is of great interest to preserve historical structures from destruction.

'Beyond its elements each building is defined by certain patterns of relationships among the elements'. 'Each one of these patterns is a morphological law, which 
establishes a set of relationships in space', each 'neighbourhood is defined, too, in everything that matters, by the patterns which keep on repeating there.

'But in a courtyard where the pattern of the opening (...) and crossing paths is missing there are forces which conflict in such a way that no one can resolve them for himself' (Alexander, 1979). 'Isn't it true that the features which you remember in a place are not so much peculiarities, but rather the typical, the recurrent, the characteristic features' (Alexander, 1979); similarly, void and modularity exist in space and function and contribute to the comprehensible distinctiveness of a place? As no better example can be given than investigating the original architectural veracity and transparent porosity of the void.

This paper's discovery lies within the domain of dominant patterns that can be encoded as a hidden grid over the changing urban setting in Sidon. In this regard, we would like to state that renovation should be guided by the patterns found in the city, so that there is nothing other than the original pattern spread throughout the landmarks of old Sidon.

\section{REFERENCES}

Christopher, A. 1979. The Timeless Way of Building.

EuroMed .2006. Non-Governmental Platform.

Ghoussayni, F. Ali, A. Bayyati, A. 2018. Findings of Patterns in Pre-historic Architecture - Case Study of the Pyramid of Cheops.

Carl Eiselen, F. 1907. Sidon: A Study in Oriental History.

Bencivengo, G. 2012. Beyond the Object: The Phenomenon of Memory in Architecture.

Al-Harithy, H. 2013. Saida Urban Sustainable Development Strategy, Strategic Diagnosis Report.

Lebanese University. 2003. Maison Laboratoire de Saida.

M. Mohamed. 2000. Great Muslim Mathematicians.

Maps and the Historical Topography of Beirut. 2006.

Kihtir Ozturk, P. 2006. Urban Transformation of Ottoman Port Cities in the Nineteenth Century: Change from Ottoman Beirut to French Mandatory Beirut.

Baumgartner, P. Richard, S. 2014-2015. Pursuit of Pattern Languages for Societal Change - PURPLSOC. The Workshop 2014. PURPLSOC. Krems, paper by Neis, Hans Joachim (From a Pattern Language to a Field of Centres and Beyond: Patterns and Centres, Innovation, Improvisation and Creativity.

Weber, S. 2002-2003. 'An Agha, a House and the City: The Debbané Museum Project and the Ottoman City of Saida, first report.

Abdullahi, Y. Rashid BinEmbi, M. 2013. Evolution of Islamic Geometric Patterns. 